\title{
Surgical lung cancer patients' views about smoking and support to quit after diagnosis: a qualitative
}

study.

Amanda Farley, ${ }^{1}$ Lecturer in Epidemiology

Paul Aveyard, ${ }^{2}$ Professor of Behavioural Medicine

Amy Kerr, ${ }^{3}$ Research Nurse

Babu Naidu, ${ }^{1,3}$ Thoracic Surgeon

George Dowswell, ${ }^{1}$ Research Fellow

${ }^{1}$ College of Medicine and Dentistry, University of Birmingham, Edgbaston, Birmingham. B15 2TT, UK

${ }^{2}$ Department of Primary Care Health Sciences, University of Oxford, Radcliffe Observatory Quarter, Woodstock Road, Oxford. OX2 6GG, UK

${ }^{3}$ Medical Innovation Development Research Unit (MIDRU), Heart of England NHS Foundation Trust, Bordesley Green East, Birmingham. B9 5SS, UK

Correspondence to: Amanda Farley a.c.farley@bham.ac.uk 01214148611

Word count: 3899

Key words: smoking cessation, lung cancer, patients preferences, qualitative

\section{Compliance with Ethical Standards}

Prof. Aveyard reports grants from UK Centre for Tobacco Control Studies (UKCRC), grants from NIHR School for Primary Care Research, during the conduct of the study; personal fees from Pfizer, personal fees from McNeil, outside the submitted work; Amanda Farley reports grants from UK Centre for Tobacco Control Studies (UKCRC), grants from NIHR School for Primary Care Research, during the conduct of the study; Babu Naidu reports grants from NIHR School for Primary Care Research, during the conduct of the study; Amy Kerr and George Dowswell report no support from any organisation for the submitted work; no financial relationships with any organisations that might have an interest in the submitted work in the previous three years, no other relationships or activities that could appear to have influenced the submitted work. 
All procedures performed in studies involving human participants were in accordance with the ethical standards of the institutional and/or national research committee and with the 1964 Helsinki declaration and its later amendments or comparable ethical standards. We were granted ethical approval by the Birmingham, East, North and Solihull Research Ethics Committee (REC ref no: 09/H1206/4). Informed consent was obtained from all individual participants included in the study.

\section{Funding}

The study was funded by the National Institute for Health Research (NIHR) School for Primary Care Research (SPCR). AF and PA were also part funded by The UK Centre for Tobacco and Alcohol Studies, a UKCRC Public Health Research: Centre of Excellence. Funding from British Heart Foundation, Cancer Research UK, Economic and Social Research Council, Medical Research Council, and the Department of Health, under the auspices of the UK Clinical Research Collaboration, is gratefully acknowledged. The views expressed are those of the author(s) and not necessarily those of the NHS, the NIHR or the Department of Health. 


\section{ABSTRACT}

\section{Purpose}

Evidence suggests that quitting smoking improves symptoms, disease related and mortality outcomes for cancer patients. However, smoking cessation support is not well integrated into routine cancer care. We explored surgical lung cancer patients' views about smoking and about their preferences for support to help them to quit.

\section{Methods}

We conducted semi-structured, qualitative interviews with 22 surgical lung cancer patients with a smoking history, after treatment with surgery. Data were analysed using the framework approach.

\section{Results}

Although diagnosis promoted a successful quit attempt in some, others continued smoking or relapsed after a quit attempt. Most participants wished they were a non-smoker, but in conflict with this also felt that smoking was enjoyable, helped with psychological coping or had some health benefits. Some also demonstrated a fatalist attitude towards the potential detrimental health effects. However, all participants felt that it was important for health professionals to address smoking and some wanted cessation support although it was often not provided. Participants wanted support to start as early as possible and to continue for the first weeks after discharge.

\section{Conclusions}

Surgical lung cancer patients often stop smoking during hospitalisation, and many want to remain quit but relapse shortly after discharge. Although it is often not provided, many patients want to be offered support to help them quit.

\section{Implications for cancer survivors}

Surveys suggest clinicians believe that addressing smoking will be difficult and/or unwanted. However, these findings suggest that surgical lung cancer patients would tolerate, and most would prefer, integration of smoking cessation support into routine cancer care. 


\section{INTRODUCTION}

Smoking is the main risk factor for lung cancer, increasing the risk of developing all main histological tumour sub-types.[1,2] Currently, around 85\% of lung cancers diagnosed in the UK are caused by cigarette smoking.[3] Estimates of the proportion of patients who are smoking at diagnosis and who continue to smoke after treatment vary. A recent US survey of 2456 surgical and non-surgical lung cancer patients reported that $39 \%$ of all lung cancer patients were current smokers at the time of diagnosis, and $14 \%$ were smoking five months after diagnosis.[4] Other surveys of surgical patients have found that between 37-60\% were current smokers at diagnosis, of which 5-48\% continued to smoke at follow up.[5-7]

Although overall survival for lung cancer is poor, five year survival after radical treatment can be as high as 70\%.[8] Continued smoking after a diagnosis of early stage lung cancer has been associated with poorer posttreatment outcomes, including worse overall quality of life (QOL),[9] increased pain,[10] increased risk of postoperative complications,[11] longer length of hospital stay,[12] and increased risk of disease progression and mortality.[13] Although smoking cessation may improve quality of life and health outcomes, two recent international surveys of clinicians involved in cancer care found that less than half routinely offered or referred patients for smoking cessation support.[14,15]

One commonly cited barrier that may prevent health professionals from offering patients smoking cessation support is that addressing smoking will be difficult and/or unwanted by the patient.[14-16] However, no study has assessed whether this is true. We interviewed surgical lung cancer patients with a smoking history to explore their views about smoking after diagnosis, and about being offered smoking cessation support as part of their cancer care.

\section{METHODS AND MATERIALS}

We obtained ethical approval to conduct this study from the Birmingham, East, North and Solihull Research Ethics Committee. Surgical lung cancer patients from one regional centre who had undergone video assisted thoracic surgery (VATS) or open thoracotomy, with or without adjuvant therapy, were invited for interview . The aims of the interviews were to explore patients' health experiences after surgical treatment for lung cancer and their views about after care. As part of this wider aim, participants with a history of smoking were also asked to describe their smoking behaviour before and after diagnosis, their views about their smoking and their 
preferences for smoking cessation support as part of cancer care. This paper reports on these smoking related findings.

Interviews took place between 3 and 14 months after surgery between Feb 2010 and Nov 2011. Patients were purposively sampled to represent a range of demographic and clinical characteristics. These included age, gender, tumour histology, primary incision procedure (VATS or open thoracotomy), and extent of resection. Participants were not sampled based on their smoking characteristics. A research nurse/physiotherapist contacted patients to assess willingness to participate in the study, and willing patients were contacted by researchers to set up an appointment to interview them in their home. Participants were interviewed following a semi-structured interview topic guide by AF. Anonymised interview transcripts were analysed using the Framework Approach.[17] Coding trees of themes based on the interview aims and emerging subthemes were iteratively constructed using NVivo 9.2 (2011 QSR International). During the early stages, five transcripts were coded by an additional researcher (GD) to check for reliability of the coding structure. Assignment of codes correlated highly between researchers and any coding differences were resolved by discussion. In addition to coding the data, a query was run in NVivo of smoking related terms to cross check the coded data. Data were summarised along with illustrative quotes in a framework matrix. Individual participants were allocated a sequential number and during analysis were referred to by the number with the prefix PN (participant number).

\section{RESULTS}

\section{Characteristics of participants and smoking patterns}

Twenty two participants were included in the analysis, all of which had a history of regular smoking. Twelve participants were male and mean age at interview was 69 years (range 39-82 years). Seventeen participants had undergone a thoracotomy and five VATS. Ten participants had undergone a wedge resection, ten a lobectomy, and two a pneumonectomy (Table 1). 
Table 1: Demographic, clinical and smoking characteristics of included participants

\begin{tabular}{|c|c|c|c|c|c|c|c|c|}
\hline Participant & Gender & $\begin{array}{c}\text { Age } \\
\text { (years) }\end{array}$ & MPS & Procedure & $\begin{array}{l}\text { Resection } \\
\text { type }\end{array}$ & $\begin{array}{l}\text { Smoking } \\
\text { pattern }\end{array}$ & $\begin{array}{c}\text { Length } \\
\text { ex- } \\
\text { smoker }\end{array}$ & $\begin{array}{l}\text { Post-discharge } \\
\text { smoking }\end{array}$ \\
\hline \multicolumn{9}{|c|}{ Current smoker at diagnosis } \\
\hline PN 5 & M & 67 & 10 & thoracotomy & 1 & 4 & $\mathrm{n} / \mathrm{a}$ & $\begin{array}{c}\text { Relapsed after period } \\
\text { of abstinence }\end{array}$ \\
\hline PN 7 & M & 77 & 6 & thoracotomy & 1 & 3 & $\mathrm{n} / \mathrm{a}$ & $\begin{array}{l}\text { Continued to smoke } \\
\text { from discharge }\end{array}$ \\
\hline PN 9 & $\mathrm{~F}$ & 71 & 9 & VATS & 1 & 3 & $\mathrm{n} / \mathrm{a}$ & $\begin{array}{l}\text { Continued to smoke } \\
\text { from discharge }\end{array}$ \\
\hline PN 13 & $\mathrm{~F}$ & 66 & 5 & thoracotomy & 2 & 4 & $\mathrm{n} / \mathrm{a}$ & $\begin{array}{c}\text { Relapsed after period } \\
\text { of abstinence }\end{array}$ \\
\hline PN 15 & M & 75 & 5 & thoracotomy & 3 & 5 & $\mathrm{n} / \mathrm{a}$ & Continually abstinent \\
\hline PN 16 & $\mathrm{~F}$ & 58 & 5 & thoracotomy & 3 & 4 & $\mathrm{n} / \mathrm{a}$ & $\begin{array}{c}\text { Relapsed after period } \\
\text { of abstinence }\end{array}$ \\
\hline PN 17 & M & 80 & 3 & thoracotomy & 5 & 5 & $\mathrm{n} / \mathrm{a}$ & Continually abstinent \\
\hline PN 18 & $\mathrm{~F}$ & 63 & 3 & thoracotomy & 3 & 3 & $\mathrm{n} / \mathrm{a}$ & $\begin{array}{l}\text { Continued to smoke } \\
\text { from discharge }\end{array}$ \\
\hline PN 20 & M & 61 & 7 & thoracotomy & 3 & 3 & $\mathrm{n} / \mathrm{a}$ & $\begin{array}{l}\text { Continued to smoke } \\
\text { from discharge }\end{array}$ \\
\hline PN 21 & $\mathrm{~F}$ & 72 & 4 & thoracotomy & 2 & 5 & $\mathrm{n} / \mathrm{a}$ & Continually abstinent \\
\hline \multicolumn{9}{|c|}{ Ex-smoker at diagnosis } \\
\hline PN1 & M & 70 & 3 & VATS & 3 & 1 & $11 \mathrm{y}$ & Continually abstinent \\
\hline PN 2 & $\mathrm{~F}$ & 81 & 4 & VATS & 1 & 1 & $20 \mathrm{y}$ & Continually abstinent \\
\hline PN 3 & $\mathrm{~F}$ & 73 & 4 & VATS & 1 & 1 & $3 y$ & Continually abstinent \\
\hline PN 4 & M & 62 & 11 & thoracotomy & 1 & 1 & $20+y$ & Continually abstinent \\
\hline PN 6 & $\mathrm{~F}$ & 61 & 14 & thoracotomy & 1 & 2 & $2 \mathrm{~m}$ & $\begin{array}{l}\text { Relapsed after period } \\
\text { of abstinence }\end{array}$ \\
\hline PN 8 & $\mathrm{~F}$ & 66 & 11 & thoracotomy & 5 & 1 & $8 \mathrm{~m}$ & Continually abstinent \\
\hline PN 10 & $\mathrm{~F}$ & 39 & 7 & thoracotomy & 4 & 1 & $15 \mathrm{y}$ & Continually abstinent \\
\hline PN 11 & M & 70 & 4 & thoracotomy & 4 & 1 & $10 \mathrm{y}$ & Continually abstinent \\
\hline PN 12 & M & 76 & 5 & thoracotomy & 3 & 1 & $32 \mathrm{y}$ & Continually abstinent \\
\hline PN 14 & M & 82 & 5 & thoracotomy & 4 & 1 & $16 \mathrm{y}$ & Continually abstinent \\
\hline PN 19 & M & 76 & 4 & thoracotomy & 1 & 1 & $20 \mathrm{y}$ & Continually abstinent \\
\hline PN 22 & M & 74 & 4 & VATS & 3 & 1 & $30+y$ & Continually abstinent \\
\hline
\end{tabular}

M= Male; F=Female; MPS=Months post-surgery at time of interview; VATS= video assisted thoracic surgery;

Surgery type: 1 = wedge resection, 2 = bi-wedge resection 3=lobectomy, 4 = bi-lobectomy, 5 =

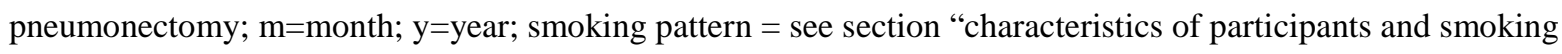
patterns”

Five broad patterns of smoking emerged from the descriptions given by participants of their smoking history and smoking after diagnosis: (1) Long term ex-smokers ( $\geq 8$ months) who did not resume smoking after diagnosis (2) Short term ex-smokers (<8 months) who did resume smoking after diagnosis (3) Current smokers at diagnosis who decided to resume smoking on discharge from hospital (4) Current smokers at diagnosis who 
attempted to quit but relapsed after a period of abstinence in the weeks following discharge from hospital (5)

Current smokers at diagnosis who quit and remained abstinent (Table 1).

Most current smokers at diagnosis reported that they had not smoked whilst an inpatient as they had felt too ill or had not wanted to smoke. Those who relapsed described smoking one cigarette and thereafter limiting their smoking but this limit gradually increased until most were smoking the same amount as prior to surgery. All relapsed within three months of discharge. Participants who resumed smoking on discharge often reported trying to cut down the number of cigarettes they were smoking but that they were not ready to quit completely.

\section{Views about smoking}

No long term ex-smoker described any benefits associated with smoking. Some expressed dislike of smoking, explaining that they were thankful that they no longer smoked and some added that they wished they had never started in the first place. Regardless of the stress experienced due to their diagnosis and treatment, longer term quitters reported that smoking was not an issue and "it never occurred" to them to start smoking again. One participant who had quit two months before diagnosis (short term ex-smoker) reported relapsing to smoking 40 cigarettes per day three months after discharge. This participant emphasised benefits of smoking such that it provided stress relief (see below).

Current smokers at diagnosis generally stated that they would prefer to be a non-smoker. Participants who had been continually abstinent from discharge reported that they had "felt like a different person" and were able to "just throw away the cigarettes" with little conflict:

"[I] packed up the day I went in hospital...I started smoking when I was twelve...sixty seven years. When I had this operation, I thought, smoking isn't going to do me any good at all, I've only got one lung, if something happens to that I'm going be in trouble, so I just said I wouldn't smoke anymore. And I won't... I shan't smoke again...I wish I could have taken that [decision] thirty years ago but there you are, that's hindsight isn't it?" PN17

However, participants that either continued smoking immediately on discharge or relapsed after a period of abstinence expressed conflict between a desire to stop and views that supported continued smoking. 
Lack of will power

Some cited no benefits for continuing to smoke but even so felt that they lacked the will power to overcome the addiction. These participants either resumed smoking immediately on discharge or had tried to remain quit but had relapsed and then felt they did not currently have the will power to try again:

"I knew I'd got a pack somewhere. And I sat here for quite a while [on the day of discharge]. And I thought, I wonder if it'll hurt if I, I wonder if it'll actually... physically hurt. I thought, I've got to have a cigarette. And I did, and it didn't hurt, so you know, stupid. Don't make any sense whatsoever... I just feel bad about it, but I can't do anything about it.... I've got the best intentions in the world, I could open a cupboard there, and show you every stop smoking product known to mankind. But none of them work... [cigarettes are] the thing I reach for." PN18

Enjoyment, psychological coping and fatalism

Some reflected on smoking with fondness. For example, PN15 quit on admission to hospital and was determined to remain abstinent but still referred to cigarettes as "an old friend". PN7 resumed smoking after discharge from hospital, although he described it as "stupidity", but also reflected that “...like I say I've had my fun, keep it quiet I've had my kicks..."

All participants who relapsed reported returning to smoking to help with psychological coping with cancer and/or non-cancer related stresses. Three lived alone and felt that this had contributed to their relapse: "You get the fuss when you first come out, everybody's knocking the door...then it all wears off and you're left suddenly on your own... and I think that's why. I started off with 10 and I ended up now since last year going up to $40 .$. Don't forget I wasn't able to do anything, much cleaning or anything because I was too weak...I was too tired so I was just lying about most times...you can't watch the telly 24/7...so that was the reason why I think I started to smoke again, boredom... But...you've got to put yourself in my position... it's like your own little prison...I always called my cigarette my comfort hat...Anytime you feel wound up or anything, have a cigarette...and I know it's no good for your lungs...but people need to understand it is a calmer...it keeps you together sometimes...at the end of the day it keeps you sane." PN6 
"With me, I think a lot of it is psychological and the fact that I sit here on my own and get fed up, 'cause I can be in a hospital for a fortnight and it won't even bother me... You know, but when you're here you just reach out, don't you." PN13

"Something made me start worrying... it just started building up, having to ring for ambulances to get to the hospital for blood and this that and the other. And it more or less got on top of me.... I've got to have a cigarette, so I did. I had one and then of course the craving came back 3 o'clock in the morning, I've got to have a fag... but you don't give in. Same first thing in the morning... the craving's there all the time." PN5

"I did really well during my treatment and surgery but over this last couple of months because there's been a lot of conflicts in the family and losing my dad, that has been very difficult and I have sort of [pause 1 sec] had the odd cigarette...I don't smoke in front of my children but I do have the odd one or two, not as much as what I did but...that's still a battle for me. I just know I've still got it kick that, but it is a battle.” PN16

Some were fatalistic towards the health consequences, placing more value on the immediate perceived mood enhancing qualities of cigarettes:

“... and I'm sixty six...I don't expect to live much longer. And when you see this world, I don't know whether I want to. I'm alright.... I just want to be happy and if a cigarette makes me happy, why shouldn't I have one. ...I know I'm naughty and I shouldn't do it... but I'm ok." PN13

“If I haven't got my cigarettes I might as well just...pack up life. I can't sit here, if you'd have seen me this morning... I've always got something I'm doing, and if they were going to make me sit here and do nothing then I didn't see any reason for me to live. And those were the doubts...I took the chance.” PN9

Perceived health benefits

Some participants who had relapsed to smoking felt that in some ways smoking was benefitting their health. This was not given as a primary reason for returning to smoking, rather justification for continuing to smoke once relapsed. For example, PN5 explained that smoking made him cough and he found that this helped clear his lungs of mucus. PN13 reported that she had known people who had given up smoking and then shortly afterwards had a stroke, which she attributed to quitting. In addition, PN13 explained that she was concerned 
that she would gain weight, and that this would compound difficulties she already experienced with mobility due to arthritis.

\section{Views about being asked to disclose smoking status to health professionals}

Many current smokers at diagnosis reported that they had not been asked about smoking at any stage of their hospital treatment. However, without exception, all participants felt that it was appropriate and important for health professionals to discuss smoking with them. Despite feeling this way, some reported that being asked had made them feel uncomfortable:

"I felt ashamed. I've done this to myself you know. It's my fault I've got it...I don't think anyone realises how addictive it is and I feel it should be banned, cause it's a drug, you know... I couldn't give it up so. But I did in the end, but too late."

PN8

Some participants had been asked about smoking by their general practitioner. One recent ex-smoker admitted she was not truthful. Her records showed that she was a non-smoker at diagnosis and she reported that it had taken her 12 months to "confess" that she had relapsed after discharge:

"It's hard because [my GP has] been very good with me. You feel like you're wasting their time, you feel guilty but she was great with me and she...asked me what I wanted [to help me stop]." PN6

Some participants underlined the importance of how health professionals approach smoking, and emphasised that a health professional should show an understanding of how difficult it is to quit:

“Smoking, drinking, your habits, I think they have got to be in the picture. There's a way of doing it. If they've never smoked they don't know how hard it is.” PN9

“I don't mind [being asked] ... it's just that, I mean my ex-partner had never smoked and he used to nag, and that's irritating. Because if you never actually had the habit, you don't know what you're on about...because they've got no concept of what it feels like, the urge.” PN21 


\section{Views about smoking cessation support as part of cancer care}

Most current smokers at diagnosis said that it would not offend them to be offered help to quit, even if they thought that it would not work for them or that they did not need the extra support:

"I don't mind being offered that sort of help because it might be the right thing for the next person and nobody knows until the help is offered, so I could quite understand why I was offered the help but it just didn't work." PN20

Although participants did not generally express preferences for particular pharmacological/behavioural treatments, many felt strongly that they wanted help but it hadn't been available to them:

“...you do need help, you do need someone to stop you from doing it really but I mean it’s easier said than done...It was about three months after [surgery] I started to smoke [again]....It would have been nice to have been able to contact someone you know. They may have been able to talk me through or come out and give you patches at the time cause, don't forget, I couldn't get to the doctors because I was too ill, I couldn't do anything really for myself them early days. So it would have been nice for them to say well, we'll send... the district nurse round with some patches...but no, you just had to do it on your own, didn't you!” PN6"

"Drugs, drink, there's rehabilitation, they get all the help...What are people doing with us smokers then? They're telling us it's will power and we've got to do it ourselves and yet they're telling us it's bad for us" PN9

Some felt that gradual reduction would be easier than abrupt cessation, and some participants (particularly those who had continued to smoke from discharge) had tried to cut down rather than quit altogether:

"I feel I want to stop and I've cut down, I'm smoking about half what I did. With regards to stopping itself I think it's an individual thing and for me personally I think I tend to look at it as it's only me that's going to do it” PN26

In addition, all who expressed a preference felt that smoking should be addressed as soon as possible after diagnosis:

"I reckon it should be done there at the bedside. Not wait for the office after you've been discharged. I think it should start being drummed into the patients there and then who are smokers. . we can help you with it... I 
think straight, at the bed, you know as soon as they are well enough to take it . . on board... You know the seriousness of it and everything else.” PN6

Other participants explained that it was important for support to continue after discharge: “Obviously you're not smoking in hospital and from the point of that, which you've done so well, it should continue, so straight away after you've come out of hospital. I mean if you've managed to do it for that long, that's probably what you need . . to inspire you to carry on.” PN16

\section{DISCUSSION}

Although a diagnosis of lung cancer triggered a successful quit attempt for some, others continued smoking or relapsed within three months of discharge, sometimes at a reduce number per day. Those who had quit in the months leading up to diagnosis were vulnerable to relapse after discharge, whereas ex-smokers of eight months or more did not contemplate returning to smoking. All participants wished they were non-smokers, or were glad they had quit. However, some also expressed several views that supported continued smoking. Regardless of these views, all felt it was important for health professionals to address smoking and to offer smokers ongoing support to quit, even if they might choose not to accept it. However, participants felt that it was important that health professionals understand the difficulty involved in successful quitting.

This is the first study to describe surgical lung cancer patients' views towards smoking and smoking cessation support after diagnosis. A key strength of this study is the diversity of the sample, which represented a broad range of smoking patterns, demographic and clinical characteristics. Given the range of characteristics that are represented in the sample, the key findings are likely to be highly generalizable. Some findings were based on a small number of participants only, for example two participants had quit within a year of diagnosis. Although the findings indicated that smokers of less than eight months prior to diagnosis were vulnerable to relapse, suggesting that recent quitters should also be closely monitored, further studies are need to more robustly ascertain the length of pre-diagnosis quitting most strongly associated with relapse after treatment. In addition, there was evidence that patients may rely on the effects of acute smoking to help with lung clearance and also that they may hold erroneous beliefs regarding the effects of quitting on health. This evidence emerged from two interviews. Further investigation is needed to understand if these beliefs are more common, and if health professionals need to address them. 
The findings are consistent with other studies that show that a cancer diagnosis prompts quitting. However, as has also been shown in other studies, a significant proportion of patients continue to smoke.[4-5] The range of reasons given by participants in this study for continued smoking are similar to those given by the general population of smokers,[18] most of whom have never had a life-threatening diagnosis. In a recent survey, stress relief, boredom relief and enjoyment were the most common motives for smoking, followed by control of weight.[19] This suggests that a diagnosis itself does not result in a long term change in people's beliefs about smoking. Also consistent with previous studies in cancer and other patients, some participants reported feeling guilty about their smoking [20,21] and, in particular, it was clear that this may reduce a patient's likelihood to be truthful about their smoking status. Participants also underlined the importance that health professionals demonstrated an understanding of the difficulty of quitting. This indicates that a sensitive and proactive approach is necessary to obtain patients true smoking status and to help them successfully engage with smoking cessation support. Due to the highly addictive nature of nicotine, patients may need repeated offers of help before they successfully quit as tobacco smoking is a chronic relapsing condition. [22]

We found that participants found it easy to be abstinent in hospital but relapsed at home. Although no strong preferences regarding type of pharmacological aids were expressed, many had a strong preference that support should begin as soon as possible after diagnosis and that it should extend during the immediate post-surgical period, because of particular vulnerability to relapse during this time. There are several reasons to suggest that quitting before surgery and extended follow up would be beneficial, in addition to being preferred by patients. First, there is evidence that quitting smoking more than four weeks before surgery leads to reductions in risk of post-operative complications, $[23,24]$ and quitting has also been associated with improved quality of life and cancer outcomes.[9-13]Secondly, there is strong evidence that extended follow up significantly increases long term quit rates. A Cochrane review that assessed the effectiveness of smoking cessation interventions in hospitalised patients found that, of five levels of intervention intensity, the only level that resulted in a significantly increased long term quit rate started at the bedside and continued for at least one month after discharge (RR 1.37 (95\% CI 1.27 to 1.48; 25 trials). This level of support was also significantly improved with supplementation of nicotine replacement therapy (RR 1.54 (95\% CI 1.34 to 1.79); six trials).[25] A second Cochrane review reporting evidence from 5 trials $(n=535)$ of a pre-surgical smoking cessation intervention also found that intensive, but not brief, intervention led to significantly increased quit rates at 12 months (RR 2.96 
(95\% CI 1.57, 5.55).[26] Third, recently published NICE guidance recommends that patients admitted to hospital (regardless of diagnosis) should be given support to remain abstinent during hospitalisation and should be offered intensive smoking cessation support which continues after discharge.[27] Taken together, these data indicate that intervening as early as possible, and referring patients for specialist support that continues after discharge is not only preferred by patients, but is also likely to result in the best chance of quit success and improving health outcomes.

\section{CONCLUSION}

Although diagnosis with lung cancer acted as a trigger for a successful quit attempt in some, others wanted to cut down or quit but relapsed shortly after discharge. Universally, patients felt it was important that health professionals enquired about their smoking and were not offended by offers of support to quit. Offers of support early in the care of lung cancer patients that continues after discharge would be welcomed by many patients and is likely to increase quitting and improve quality of life and treatment outcomes. The findings of this study indicate that health professionals can address smoking directly and not fear upsetting patients, but to maximise patient engagement it should be done so sensitively. It may also be that professionals need to be flexible in their goals, for example encompass cutting down. Future research should consider how to best integrate smoking cessation support into standard care for surgical lung cancer patients. 
[1] Morabia A, Wynder EL Cigarette smoking and lung cancer cell types. Cancer 1991; 68:9:2074-2078

[2] Khunder SA Effect of cigarette smoking on major histological types of lung cancer: a meta-analysis Lung Cancer 2001; 31: $139-148$

[3] Parkin DM. Tobacco-attributable cancer burden in the UK in 2010. Br J Cancer 2011;105:S6-S13

[4] Park ER, Japuntich SJ, Rigotti NA et al. A snapshot of smokers after lung and colorectal cancer diagnosis. Cancer 2012:118:3153-3164

[5] Cooley ME, Sarna L, Kotlerman J et al. Smoking cessation is challenging even for patients recovering from lung cancer surgery with curative intent. Lung Cancer 2009; 66:218-225

[6] Dresler CM, Bailey M, Roper CR et al. Smoking cessation and lung cancer resection. CHEST journal 1996;110:11991202

[7] Gritz ER. Smoking and smoking cessation in cancer patients Brit J Addict 1991;86:549-554

[8] CRUK. Lung cancer survival rates http:www.cancerresearchuk.org/cancer-help/type/lung-cancer/treatment/statistics-andoutlook-for-lung-cancer [date of access 23/02/2015]

[9] Garces YI, Yang P, Parkinson J et al. The relationship between cigarette smoking and quality of life after lung cancer diagnosis CHEST Journal 2004;126:1733-17.41

[10] Daniel M, Keefe FJ, Lyna P et al. Persistent smoking after a diagnosis of lung cancer is associated with higher reported pain levels J Pain 2009;10:323-328 
[11] Moller AM, Villebro N, Pedersen T et al. Effect of preoperative smoking intervention on postoperative complications; a randomised clinical trial. The Lancet 2002; 359:114-117

[12] Erhunmwunsee L, Onaitis M. Smoking cessation and the success of lung cancer surgery. Curr Oncol Rep 2009; $11: 269-274$

[13] Parsons A, Daley A, Begh R et al. Influence of smoking cessation after diagnosis of early stage lung cancer on prognosis: systematic review of observational studies with meta-analysis BMJ 2010;340:b5569

[14] Warren G, Marshall J, Cummings KM et al. Practice patterns and perceptions of thoracic oncology providers on tobacco use and cessation in cancer patients. J Thorac Oncol 2013;8:543-548

[15] Warren GW, Marshall JR, Cummings KM et al. Addressing tobacco use in patients with cancer: a survey of American society of clinical oncology member Journal of Oncology Practice 2013;9:258-262

[16] Dresler CM, Gritz ER. Smoking, smoking cessation and the oncologist. Lung Cancer 2001;34:315-323

[17] Richie J, Lewis J. Qualitative research practice. 1 ${ }^{\text {st }}$ ed. Sage, 2007

[18] Taylor T, Lager D, Bryant A et al. Smoking related behaviour and attitudes. Office for National Statistics 2008-2009, 2009 http://www.ons.gov.uk/ons/rel/lifestyles/smoking-related-behaviour-and-attitudes/index.html

[19] Fidler JA, West R. Self-perceived smoking motives and their correlates in a general population sample Nicotine Tob Res 2009;11:1182-1188

[20] LoConte NK, Else-Quest NM, Eickhoff J, Hyde J, Schiller JH Assessment of guilt and shame in patients with non-small cell lung cancer compared with patients with breast and prostate cancer Clinical Lung Cancer 2008; 9:3: 171-178

[21] Halding AG, Heggdal K, Wahl A Experiences of self-blame and stigmatisation for self-inflication among individuals livings with COPD Scand J Caring Sci 2011; 25: 100-107 
[22] Steinberg MB, Schmelzer AC, Lin PN et al Smoking as a chronic disease Curr Cardio Risk 2010 4:413-420

[23] Wong J, Lam D, Abrishami A et al. Short-term preoperative smoking cessation and postoperative complication: a systematic review and meta-analysis Can J Anesth 2012;59:268-279

[24] Mason DP, Subramanian S, Nowicki ER et al. Impact of smoking cessation before resection of lung cancer: a society of thoracic surgeons general thoracic surgery database study Ann Thorac Surg 2009;88:362-371

[25] Rigotti N, Munafo MR, Stead LF. Interventions for smoking cessation in hospitalised patients. Cochrane Database Syst Rev 2012 May 16;5: CD001837. doi: 10.1002/14651858.CD001837.pub3.

[26] Thomsen T, Tonnesen H, Moller AM. Effect of preoperative smoking cessation interventions on postoperative complications and smoking cessation. Br J Surg 2009;96:451-461

[27] National Institute of Health and Clinical Excellence. Smoking cessation in secondary care: acute, maternity and mental health services. 2013;NICE guidelines [PH48] 